\title{
Looking to relate: teacher gaze and culture in student-rated teacher interpersonal behaviour
}

\author{
Nora A. Mclntyre ${ }^{1}$ (D) $\cdot$ Kees Tim Mulder ${ }^{2} \cdot$ M. Tim Mainhard ${ }^{2}$
}

Received: 18 July 2019 / Accepted: 10 December 2019 / Published online: 7 January 2020

(c) The Author(s) 2020

\begin{abstract}
Mobile eye-tracking was used to investigate the link between teacher gaze and student-rated teacher interpersonal behaviour. Teacher gaze was recorded for $10 \mathrm{~min}$ during a teacher-centred part of a naturally occurring lesson. The Questionnaire on Teacher Interaction was then administered to assess how UK students evaluated their teacher interpersonally in that lesson. Teachers conveyed greater dominance (or interpersonal agency) through increasing eye contact while asking questions ('attentional gaze'). Teachers conveyed more interpersonal friendliness (or communion) through increasing eye contact while lecturing ('communicative gaze'). Culture did not affect the way gaze was associated with students' interpersonal perceptions.
\end{abstract}

Keywords Teacher interpersonal behaviour · Eye-tracking $\cdot$ Culture $\cdot$ Real-world . Circular statistics

\section{Introduction}

Teachers make great impact. Beyond taking students through a curriculum and imparting critical skills so that they attain the qualifications they need, teachers are affecting students in every moment of classroom learning. Minute, momentto-moment behaviours create an ever-evolving picture of who the teacher is so that the classroom environment in which students learn is continually morphing (Pennings and Mainhard 2016). To empirically explore this process, intensively changing teacher behaviours should be captured and summarised. This metric can then be

Electronic supplementary material The online version of this article (https://doi.org/10.1007/s1121 8-019-09541-2) contains supplementary material, which is available to authorized users.

Nora A. McIntyre

nam58@cam.ac.uk

1 Faculty of Education, University of Cambridge, 184 Hills Road, Cambridge CB2 8PQ, UK

2 Faculty of Social and Behavioural Sciences, Utrecht University, Utrecht, The Netherlands 
related to another summary: students' perceptions of these teachers, so that associations with these dynamic behaviours are also captured.

The present paper focuses on teacher gaze, a behaviour that changes intensively indeed, often with several events per second. We then relate gaze to students' perceptions of teachers' interpersonal behaviour-the socioemotional atmosphere that teachers, by every level of their behaviour, generate. To maximise the relevance and applicability of our research, we conducted our study in real-world classrooms. We additionally explored whether the impact of teachers' behaviour on student experiences differs across cultures, thus probing the cultural generalisability of our findings.

The present article is not the first use of our teacher gaze data. Prior analyses have shed light on the many insights to be gained on teacher expertise through the multiple metrics available from teachers' real-world gaze. Teachers' priorities, knowledge, efficiency, flexibility, strategic consistency and cognitive models can all be uncovered from their gaze behaviour [PRESENT AUTHORS]. What we now report further complements our previous work by relating teacher gaze to student ratings of teacher interpersonal behaviour for the first time. Not only is the present research the first to relate teacher gaze to a major dimension of secondary students' classroom experience (Eccles et al. 1993), but we report the first use of circular statistics (Gurtman 2009) within educational science, in accordance with the circular structure of our framework for understanding teachers' interpersonal behaviour, namely the Teacher Interpersonal Circle (Sun et al. 2018; Wubbels et al. 2014).

\subsection{Teacher interpersonal behaviour}

Teachers' interpersonal behaviour plays an important role in students' learning experiences. Deci refers to an optimal "interpersonal ambience" which enables students to take ownership of their learning (Deci et al. 1991, p. 336). It has even been argued that young people "live for their social relationships" (Pianta et al. 2012, p. 369). Teachers' interpersonal behaviour plays a major role in students' intrinsic motivation (Lawson and Lawson 2013) and can, in turn, affect student outcomes such as depth of learning (Vansteenkiste et al. 2004; Wubbels et al. 2016) and self-regulation (Pintrich et al. 1994).

What is the nature of this powerful construct? According to Interpersonal Theory (Horowitz and Strack 2010), interpersonal behaviour is comprised of two dimensions, agency (i.e., power and dominance) and communion (i.e., friendliness and warmth). These are orthogonal to each other and join to form teacher interpersonal behaviour. Within this framework, teacher interpersonal behaviour takes a circular structure, such that the construct is also known as the Teacher Interpersonal Circle (Sun et al. 2018, Fig. 1).

When interpreting the Teacher Interpersonal Circle, we can talk in terms of competing levels of agency versus communion. When agency and communion are both high, interpersonal behaviour is positive and located in the top right quadrant (i.e., octants 1 and 2, or directing and helping, cf. Fig. 1). In this scenario, agency that is higher than communion specifies that the teacher is being directing (Octant 1) 


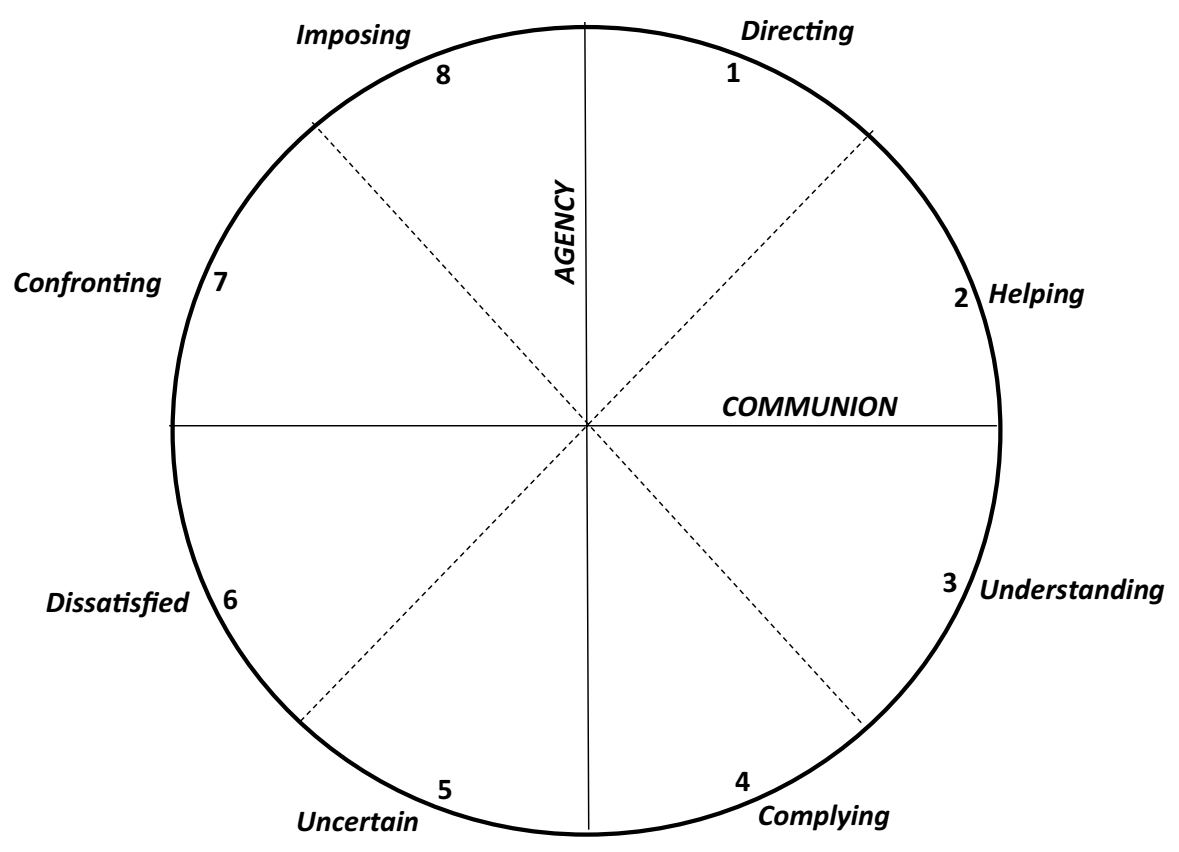

Fig. 1 The interpersonal circle for teachers (IPC-T)

whereas communion that is higher than agency specifies helping behaviour (Octant 2). In other words, comparative levels of agency and communion specify the precise octant to which a teacher's interpersonal behaviour belongs (e.g., den Brok et al. 2010; Maulana et al. 2014).

We further contend that interpretations of teachers' interpersonal behaviour should account for the circular structure of the Teacher Interpersonal Circle. The need for this rigour emerges from the differing assumptions that circular theories make in contrast to linear theories: whereas linear theories would regard dimensions within one measure to be separate and distinct from one another, circular theories suppose dimensions to interrelate; whereas linear theories conceptualise behaviour as flat and one dimensional, circular theories view behaviour in terms of a circumference around a circle (Larsen and Diener 1992) and in terms of angles (Alden et al. 1990). Accordingly, contributing factors to teachers' interpersonal behaviour either move them clockwise or anticlockwise. In other words, once we have identified the broad location of a teacher's interpersonal behaviour in general (e.g., 'teachers in this sample are directing, helping and understanding, cf. Fig. 1), we should then examine the direction in which a contributing factor (e.g., cultural group) moves the teacher's interpersonal behaviour (e.g., anticlockwise, i.e., being more directing and less understanding). 


\subsection{Teacher gaze and teacher interpersonal behaviour}

Teachers send signals through both their verbal behaviour and nonverbal behaviour, according to the Teacher Interpersonal Circle (Van Tartwijk et al. 1998). In support, non-educational studies have shown that nonverbal behaviours are related to others' interpersonal perceptions of ourselves (DePaulo and Friedman 1998) and that our direct gaze at other people is a primary channel for sending interpersonal signals (Einav and Hood 2008). Specifically, direct gaze grabs attention, signalling leadership and agency (Ohlsen et al. 2013). Direct gaze also increases communion: that is, others' sense of connection with ourselves (Wirth et al. 2010) and one's likeability (Mason et al. 2005).

Educational studies give recognition to teachers' direct gaze towards students as one channel of nonverbal instructional behaviours (Richmond et al. 1987). In terms of agency, direct gaze has been associated with teacher credibility (Johnson and Miller 2002) and authority (Turman and Schrodt 2006) as well as student validation (Kerssen-Griep and Witt 2012) as rated by students. The more teachers use direct gaze, the more students like them (Chesebro 2003). These are important effects, as students' interpersonal experiences in the classroom significantly affect their academic motivation (Slof et al. 2016).

Previous studies on teacher gaze identified direct gaze through subjective observation. Through mobile eye-tracking, the present paper makes first use of objective measures regarding teacher gaze in relation to their interpersonal behaviour. Thus, we avoid errors based on the angle from which a human observer is watching the teacher. We take full advantage of the eye-tracker's consistent angle and internal algorithm in the calculation of teachers' gaze directions. Moreover, in line with the call for a distinction between attentional (i.e., information-seeking) versus communicative (i.e., information-giving) gaze (Jarick and Kingstone 2015), the present study examined the differing role of each gaze type in student perceptions of teacher interpersonal behaviour.

\subsection{Culture, gaze and teacher interpersonal behaviour}

Teachers' nonverbal behaviour is likely to depend on their culture to some degree. ${ }^{1}$ Compared with East Asians, Westerners tend to display greater emotional intensity (Matsumoto et al. 1988; Uchida and Kitayama 2009). This East-West distinction has been explained by the collectivistic priority given to the group over oneself in East Asia, in contrast to the emphasis placed on the individual's expression (Markus and Kitayama 1991). Consequently, significant differences have already been reported

\footnotetext{
${ }^{1}$ Due to the limited literature on interpersonal behaviour and gaze that is specific to Chinese populations, we discuss cultural differences in terms of Western Europeans and East Asians in this article. This approach to grouping countries such as the UK, Finland and France as Western Europeans (or, when including Canadians and North Americans, Westerners) and Chinese, Japanese and Koreans as East Asians is supported by cultural research on teaching and learning (e.g., Hofstede 1986) as well as gaze (e.g., Akechi et al. 2013).
} 
on cultural differences in the use of gaze. It is postulated that the importance of culture in gaze patterns would also be detected among teachers in the real-world classroom setting.

Cultural differences have been documented in the signals that gaze directions send. Whereas 'I am knowing' (i.e., assertive or confident) is signalled by sustained direct gaze among Westerners (i.e., Canadians), it is signalled by shorter direct gaze among East Asians (i.e., Japanese, McCarthy et al. 2006). In contrast, the message, 'I am thinking' (i.e., uncertainty or lack of confidence), is signalled by upward, averted gaze among Westerners and downward, averted gaze among East Asians (McCarthy et al. 2008). Furthermore, direct gaze is interpreted as being more unpleasant by East Asians than by their Western counterparts, such that anger and unapproachability are detected from direct gaze only by East Asian participants (Akechi et al. 2013). The same gaze behaviour therefore sends different signals in different cultures during information-giving, or 'communication' (see Sect. 2.5 for more details on the distinction between communicative and attentional gaze).

Cultures also differ in the areas to which they give particular attention during information-seeking episodes (cf. Sect. 2.5). When shown interpersonal stimuli such as faces, Western participants display gaze that is scattered across the face. In contrast, East Asians focus their attention on the nose, a central position in the facial image (Blais et al. 2008). This effect occurs even when facial images are inverted (Kelly et al. 2008). In fact, it seems that Westerners use more information from the eyes but East Asians take more information from the nose region (Miellet et al. 2013). Moreover, direct gaze is detected and avoided more quickly by East Asians than Western Europeans (Jack et al. 2012). Thus, we seem to handle the same interpersonal stimuli differently depending on our cultural background.

\subsection{The present study}

Students are relational beings (Deci et al. 1991) whose experiences of classroom learning will be shaped significantly by every level of teachers' behaviour. Since teacher gaze is likely to play a part in this process (Csibra and Gergely 2009), mobile eye-tracking glasses were used in the present study as an objective measure of teachers' direct gaze towards students which we then related to students' perceptions of the eye-tracked teacher's interpersonal behaviour. By taking cultural differences in teacher interpersonal behaviour into account, the present article further extends preceding literature on variations in culturally appropriate teacher interpersonal behaviour. In sum, the present hypotheses were as follows:

Hypothesis 1 Teacher gaze will significantly predict students' ratings of teacher interpersonal behaviour (IPC-T). Given the opposing directions of information transmission during communicative versus attentional gaze, we additionally expected teachers' interpersonal behaviour to be rated in contrasting manners during communicative gaze compared with attentional gaze. As suggested in the literature, teachers' attentional gaze was expected to relate to anticlockwise-leaning teacher interpersonal behaviour (i.e., increased agency but decreased communion, 
see Fig. 1; Cortina et al. 2015). In contrast, teachers' communicative gaze on the other hand was expected to predict clockwise-leaning teacher interpersonal behaviour (i.e., decreased agency but increased teacher communion, see Fig. 1).

Hypothesis 2 Apart from gaze, students' interpersonal perceptions of their teacher was expected to differ cross-culturally. In particular, Western European teachers were likely to be perceived as clockwise-leaning (i.e., only somewhat agentic but highly communing, see Fig. 1), whereas East Asian teachers would be perceived as anticlockwise-learning in comparison to their European colleagues (i.e., more agentic and less communing, see Fig. 1; Wei et al. 2015) as represented in the IPC-T.

Hypothesis 3 To bring gaze back into focus, prior reports of cultural differences in attentional (e.g., Miellet et al. 2013) and communicative (Hofstede 1986) gaze led us to expect a significant indirect effect of culture and teacher gaze on students' ratings of teacher interpersonal behaviour.

\section{Method}

\subsection{Participants}

Forty teachers of various subjects participated: 20 from the UK ( 9 male; 11 female); 20 from Hong Kong (6 male; 14 female). Gender differences across the cultures were not likely to be important since gender did not add significantly to the overall model $(b=.13, p=.93)$.

Schools were invited to participate if they followed the national curriculum (i.e., local public schools rather than international or private schools) and if they consisted of the first to the fifth years of secondary education. The first to fifth years of secondary education were chosen across the two countries for comparability of academic grade levels. However, for each grade, students in Hong Kong are one year older than students in the UK. This age difference across cultures is inconsequential, as supported by the way it fails to significantly add to the rest of the model $(b=.02, p=.99)$.

The cultural grouping for each teacher was based on their geographical location: either in the UK ('West') or Hong Kong ('East Asia'). Two UK $\left(M_{\text {Class size }}=21.35\right)$ and two Hong Kong $\left(M_{\text {Class size }}=33.75\right)$ schools agreed to participate. All the teachers in the UK were ethnically Caucasian who had lived in Western Europe for three generations (i.e., themselves, their parents and grandparents); all the teachers in Hong Kong were ethnically Chinese who had lived in China for three generations.

To further account for variations in teaching approaches, we ensured each cultural group consisted of ten experts and ten novices. Expertise was classified based on years' experience, teaching performance ratings, social recognition and qualifications (Palmer et al. 2005). 


\subsection{Apparatus}

We used Tobii 1.0 eye-tracking glasses to record teacher gaze. Data rate was $30 \mathrm{~Hz}$, making one frame one thirtieth of a second. The eye-tracker comprised a nine-point calibration system. The glasses yielded a $640 \times 480 \mathrm{px}$ video: $56^{\circ}$ horizontally, $40^{\circ}$ vertically. This eye-tracker made simultaneous recordings of the scene, audio and gaze. The same eye-tracker was used in both cultural settings.

\subsection{Procedure}

For each participating teacher the eye-tracker was calibrated at the start of the scheduled data collection period. To protect calibration accuracy, teachers were explicitly requested not to move their eye-tracker after calibration. Each teacher was eye-tracked during one lesson only. In total, $10 \mathrm{~min}$ of teacher-centred gaze was recorded: depending on the teacher's lesson plan, their gaze was either recorded all in one instance during the lesson or across multiple occasions interspersed, with other activities such as group or individual work, during the same lesson. The eye-tracking data were manually coded by playing the gaze replay at one-eighth of the real-time speed for gaze behaviour. We also coded teachers' didactic behaviours via playback in real-time. These procedures were approved by the first author's institutional ethics review board.

\subsection{Design}

Teacher-centred sessions occur when the teacher takes the spotlight to lead the whole class as one. It contrasts with group or independent work when students take their own lead. Teacher-centred sessions seemed appropriate for the present study because, out of all possible activity types in classroom learning, teachercentred sessions contain the most teacher-specific data. Compared with other classroom activities, teacher-centred parts of learning are also least likely to differ across subjects, due to the narrow range of events that can take place, all of which is captured in our coding scheme. This claim is supported by our analysis in which subject differences did not add significantly to the rest of the model $(b=1.60, p=.45)$. Only teacher-centred learning was sampled in this study: no group work, pair work, individual seat work, or any other activity type was investigated. All teaching and learning that was not teacher-centred was not coded and excluded from analysis.

Eye-tracking took place for approximately $10 \mathrm{~min}$. Ten minutes of eye-tracking data produces an abundance of data from each participant and certainly generates enough power for analyses as the reader will see from what follows in the present report. There is already support that relatively short durations of process data are powerful in predicting overarching constructs such as teacher interpersonal behaviour (Pennings et al. 2017). 


\subsection{Measures}

\subsubsection{Gaze measures}

Measures for attentional and communicative gaze were represented by a combination of two the types of codes: gaze behaviour and didactic behaviour. Codes were applied comprehensively such that the full duration of the data were classified to constitute a specific gaze type and didactic behaviour simultaneously.

The coded gaze behaviours were student fixation (sustained direct gaze towards students; i.e., more than four key frames per student), student scan (i.e., panning gaze across students quantified as four key frames or less per student; cf. Franchak et al. 2011; Hanley et al. 2015), student material, teacher material, other (i.e., nonstudent and non-instructional) and unsampled gaze (which were excluded from analysis). Inter-observer reliability for gaze coding was good (ICC[2] = .78, 95\% CI[.59, .89]). In the present analysis, only student fixation was used: that is, teachers' sustained direct gaze towards students. Gaze duration measures were relativized by analysing the duration per visit to control for cross-teacher variations in the number of times they looked at students.

To code didactic behaviours, simultaneous verbalisations were transcribed at five second intervals. Each segment was aligned with the gaze data and coded as one of the following: address behaviour (i.e., directly instructing students to change their behaviour), attention (i.e., student or teacher asking and answering questions), communication (i.e., teachers explaining, lecturing or instructing), refer notes (i.e., teacher referring to presentation slides or students' resources), logistics (e.g., teacher moving the presentation onto another slide). In support for the reliability of this coding system, intra-observer reliability was computed. Our coder showed strong consistency in the verbal coding ( $\mathrm{ICC}[3]=.86,95 \% \mathrm{CI}[.57, .95])$.

When student fixation occurred together with attention, we coded this as attentional gaze: we thus obtained teacher attentional gaze towards students. When student fixation occurred together with communication, we coded this as communicative gaze: we thus obtained teacher communicative gaze towards students. Only these latter two gaze types were included in the current analyses. Both gaze types occurred within teacher-centred learning: that is, within the same type of classroom activity.

In all, our present analyses involved two gaze measures: attentional fixation duration per visit (henceforth attentional gaze); communicative fixation duration per visit (henceforth communicative gaze).

\subsubsection{Teacher interpersonal behaviour}

Student-reported teacher interpersonal behaviour were measured using Questionnaire on Teacher Interaction (QTI) which consisted of 48 items (six items per octant of the Interpersonal Circle for the Teacher, henceforth IPC-T) of student reports on teacher interpersonal behaviour in general such that students were not limited to rating their teachers in terms of their behaviour during the lesson in which eye-tracking data were collected. This English version was developed in Australia (Wubbels 
1993). The Chinese version was generated using a mainland Chinese sample and validated for use among Chinese speakers (Wei et al. 2009). Data inspection was conducted on both the English and Chinese QTI at the same time, with the reliability of students' questionnaire responses first assessed using Cronbach's alpha. For agency, reliability reached $\alpha=.72$; for communion reliability was $\alpha=.85$. To take into account the nested nature of the questionnaire data, intra-class correlation (ICC) was inspected among students with the same eye-tracked teacher (Lüdtke et al. 2009; Mainhard et al. 2011; Miller and Murdock 2007). Students in the present study were highly consistent with each other regarding teachers' agency $(\mathrm{ICC}[1]=.55)$ and to a lesser degree regarding communion $(\mathrm{ICC}[1]=.22)$.

The CircE package in R (Grassi et al. 2010) was employed for circular fit analyses of the student ratings of teacher interpersonal behaviour. Fit indices were satisfactory: Root Mean Square Error of Approximation =.05 (RMSEA; Brown and Cudeck 1993; Hu and Bentler 1998); Standardized Root Mean Square Residual $=.05,90 \%$ CI[.051, .054] (SRMR; Bentler 1995); Bentler (1990) CFI=.86; Bentler-Bonett $\mathrm{NFI}=.82$ (Bentler and Bonett 1980; Hu and Bentler 1999); Adjusted Goodness of Fit $=.88$ (AGFI; Jöreskog and Sörbom 1981; McDonald and Marsh 1990). This satisfactory fit is shown in Figure 1 (see Supplementary Figures), with items clustering together in their respective octants. Octants in the data were also distributed in the correct order, in accordance with the theoretical model.

In accordance with the circular structure of the Teacher Interpersonal Circle, a circular (rather than linear) score of student-rated teacher interpersonal behaviour was calculated for each teacher. Together with other teachers' aggregated scores, this served as the outcome variable in the present analyses. This circular teacher interpersonal behaviour variable was obtained by first calculating agency and communion based on the sub-scale data using SPSS-based syntax (e.g., den Brok et al. 2010). Then, a circular transformation was conducted on the agency and communion variables using the atan 2 function in $\mathrm{R}$ ( $\mathrm{R}$ Core Team 2017). The $y$ variable was agency and the $x$ variable was communion, in accordance with the IPC-T. In all, the teacher interpersonal behaviour was measured as $\theta=$ atan2(agency, communion). Support for our use of a circular transformation of agency and communion is given by Figure 2 (see Supplementary Figures) which demonstrates that a linear combination of agency and communion (i.e., using an agency $\times$ communion interaction term) would give the same values for opposing teacher interpersonal characteristics as represented by our circular measure, which would certainly have been invalid. The teacher interpersonal behaviour measure, IPC-T, was the DV in the main analyses for this paper.

\subsection{Analyses}

To account for the circular structure of teacher interpersonal behaviour (IPC-T), specialised statistical methods are required. We have already mentioned the assumptions that differ between linear and circular analyses, but there are also substantial differences in the capabilities therein. Although linear statistical methods such as principal component analysis, multidimensional scaling and multiple regression are 
easily accessible via any statistical package, along with clear graphs to indicate the presence or absence of a circular structure, linear statistics are unable to test the presence of the required circular structure empirically and numerically (Browne 1992). Furthermore, only circular statistics are able to constrain parameters in order to analyse circular data in accordance with their circular structure (Mardia and Jupp 2009; Pewsey et al. 2013): fit indices are given in terms of the circular (rather than linear) fit to locate participants' scores around the circular space (Fabrigar et al. 1997) and group tendencies can be mapped around the circle to summarise behaviours (Gurtman 2009). Hence, only circular statistics can close the gap between circular theory and the data that represents it. Therefore, circular analyses were run in accordance with the circular statistical properties of our dependent variable.

\subsubsection{Circular sequential regression}

Sequential circular regressions were conducted on the circular outcome variable of teacher interpersonal behaviour (IPC-T): the two gaze variables (attentional and communicative gaze) were entered at stage one, then culture at stage two. To conduct these circular regression analyses, the circular (Agostinelli and Lund 2017) package in $\mathrm{R}$ was used. Preliminary analyses revealed a negative (i.e., right) skewed distribution. A $\log$ transformation $(\mathrm{g}(\mathrm{x})=\log (1+\mathrm{x}))$ was therefore employed in order to meet circular analytic requirements. Moreover, a log addition of one was chosen through sensitivity analyses and used in the final analyses. For the model fit coefficient, deviance was computed from the log likelihood instead of the linear equivalent (i.e., the $R^{2}$ value). Thus, deviance and its associated information criteria were employed to compare model fit at each stage of the sequential analysis. The difference in deviance was employed to test differences between models.

\subsubsection{Circular mediation analysis}

To investigate possibilities of teacher gaze mediating culture's effect on teacher interpersonal behavior (IPC-T), exploratory mediation analyses was conducted. There were actually two mediators: attentional gaze and communicative gaze. As is customary, we computed a direct effect $(c)$ : the circular effect of culture on IPC-T. We also computed total effect $\left(c^{\prime}\right)$ : the circular effect of culture on IPC-T in a model which excludes the mediators, attentional and communicative gaze. Mediation was tested using the indirect effect which we computed as the total effect subtracted from the direct effect $\left(c-c^{\prime}\right)$ rather than the customary the combination of the path the IV (culture) to the CV (IPC-T) via the mediatory $(a b)$ since we had more than one mediator, attentional and communicative gaze (MacKinnon et al. 2002).

Additionally, we developed a non-parametric bootstrap for the circular regression model (Efron and Tibshirani 1994) which we applied to 10,000 bootstrapped data sets to obtain the mediation analytic outcome. This non-parametric formulation was necessitated by the unknown distribution of our indirect effects (Mallinckrodt et al. 2006; Shrout and Bolger 2002). The bootstrap was implemented in R (R Core Team 2017). Functions for performing this bootstrap are publicly available. 
Table 1 Correlation matrix of variables analysed in this study

\begin{tabular}{lcccccc}
\hline & Attn & Cmmn & sqrtAttn & sqrtCmmn & Culture & IPC-T \\
\hline Attn & 1.00 & $.74 * * *$ & $.99 * * *$ & $.64 * * *$ & $.43 * *$ & $.32^{*}$ \\
Cmmn & $.74 * * *$ & 1.00 & $.73 * * *$ & $.96 * * *$ & .08 & .09 \\
sqrtAttn & $.99 * * *$ & $.73^{* * *}$ & 1.00 & $.63 * * *$ & $.44 * *$ & $.36^{*}$ \\
sqrtCmmn & $.64 * * *$ & $.96 * * *$ & $.63 * * *$ & 1.00 & .01 & .06 \\
Culture & $.43^{* *}$ & .08 & $.44 * *$ & .01 & 1.00 & $.56^{* * * *}$ \\
IPT-C & $.32 *$ & .09 & $.36^{*}$ & .06 & $.56^{* * *}$ & 1.00 \\
\hline
\end{tabular}

IPC-T refers to teacher interpersonal behaviour as measured by the interpersonal circle for teachers; Attn refers to attentional gaze; Cmmn refers to communicative gaze; sqrt identifies variables that were squareroot transformed (used in linear analyses only)

$* p \leq .05, * * p \leq .01, * * * p \leq .001$.

\section{Results}

Results are organised by hypotheses, with the first hypothesis being addressed at stage one of sequential circular regression, Hypothesis 2 at stage two, and Hypothesis 3 through circular mediation analysis. Follow-up analyses were conducted to explore potential mediation by teacher gaze between culture and teacher interpersonal behaviour (IPC-T). A correlation matrix for variables in this study's analyses are found in Table 1.

\subsection{Hypothesis 1: Teacher interpersonal behaviour relates to teacher gaze}

The present teacher sample congregate within Octant 2, suggesting that teacher interpersonal behaviour was generally perceived by students as helping behaviour more than directing, understanding, or any other octant in the IPC-T. Although teacher interpersonal behaviour was distributed within one octant rather than spread over multiple octants, variation was found to be predicted by differing teacher gaze behaviour.

Hypothesis 1 specified that more attentional gaze should link with more agentic (i.e., anticlockwise-leaning on the IPC-T) teacher interpersonal behaviour, whereas communicative gaze should predict more communing teacher interpersonal behaviour (i.e., clockwise leaning on the IPC-T). As expected, increasing attentional gaze was found to predict anticlockwise-leaning teacher interpersonal behaviour at stage one, $b=.14$, s.e. $=.05, \mathrm{t}=2.87, p=.002$, whereas it was increasing communicative gaze related to clockwise-leaning teacher interpersonal behaviour, $\mathrm{b}=-.08$, s.e. $=.05, \mathrm{t}=1.49, p=.07$ (Figure 3, in Supplementary Figures). In short, the first hypothesis was supported.

\subsection{Hypothesis 2: Teacher interpersonal behaviour also relates to teacher culture}

The present spread of teacher interpersonal behaviour was limited to helping behaviour. However, Hypothesis 2 predicted that, by being British, UK teachers would be more communing (clockwise-leaning), whereas being Chinese meant that Hong 
Table 2 Descriptive statistics of teacher interpersonal behaviour scores

\begin{tabular}{|c|c|c|c|c|c|c|}
\hline & \multicolumn{2}{|c|}{ IPC-T } & \multicolumn{2}{|c|}{ Agency } & \multicolumn{2}{|c|}{ Communion } \\
\hline & M & $\mathrm{SD}$ & M & $\mathrm{SD}$ & M & SD \\
\hline \multicolumn{7}{|c|}{ Hong Kong } \\
\hline Expert & .32 & .22 & .40 & .20 & 1.30 & .33 \\
\hline Novice & .17 & .09 & .26 & .11 & 1.52 & .20 \\
\hline Total & .25 & .18 & .33 & .17 & 1.41 & .29 \\
\hline \multicolumn{7}{|l|}{ UK } \\
\hline Expert & .47 & .06 & .81 & .15 & 1.59 & .15 \\
\hline Novice & .39 & .09 & .62 & .15 & 1.48 & .19 \\
\hline Total & .43 & .08 & .71 & .18 & 1.54 & .18 \\
\hline
\end{tabular}

IPC-T refers to teacher interpersonal behaviour as measured by the interpersonal circle for teachers

Kong teachers would be more agentic (anticlockwise-leaning) in their interpersonal behaviour. However, the UK culture was instead found to predict anticlockwiseleaning IPC-T ratings. It was being Chinese that predicted clockwise-leaning teacher interpersonal behaviour, $\mathrm{b}=.08$, s.e. $=.03, \mathrm{t}=3.08, p=.001$. In other words, contrary to expectation, students perceived UK teachers to be more agentic than Hong Kong teachers. Hong Kong teachers were perceived as more communing by students than their UK counterparts (see Figures 4 and 5, in Supplementary Figures). The directions anticipated by Hypothesis 2 was directly contradicted by the present data, although the importance of culture was supported.

The overall model at stage two was a significant improvement on stage one, $\Delta$ Deviance $=8.52, p=.004$. See Table 2 for descriptive statistics for each cultural group's interpersonal behaviour score and Table 3 for all coefficients in the circular sequential analysis.

\subsection{Hypothesis 3: Teacher interpersonal behaviour is predicted by teacher culture via teacher gaze}

Circular analysis found neither attentional nor communicative gaze to predict IPC-T significantly $(p=.18-.37)$, suggesting culture to be a confound in the gaze-IPC-T relationship and challenging expectations set out in Hypothesis 3. To confirm mere confounding by culture, the hypothesised indirect effect of culture via teacher gaze (i.e., attentional gaze and communicative gaze) was obtained. The total indirect effect of culture via teacher gaze was not statistically significant $(b=.01, p=.26)$; neither was the individual indirect effect of culture via attentional $(p=.25)$ or communicative $(p=.80)$ teacher gaze. Circular mediation analysis thus showed that teacher gaze did not mediate the effect of culture on teacher interpersonal behaviour, thereby opposing Hypothesis 3. Instead, culture is suggested to be a common cause of teacher gaze and interpersonal behaviour (Figures 6 and 7, in Supplementary Figures). 
Table 3 Circular sequential regression of attentional gaze, communicative gaze and culture predicting teacher interpersonal behaviour

\begin{tabular}{|c|c|c|c|c|c|c|c|}
\hline IV & Deviance & $\Delta$ Deviance & $p$ & $\mathrm{~b}$ & s.e & $\mathrm{t}$ & $p$ \\
\hline Stage one & 186.32 & - & - & - & - & - & - \\
\hline Attention & - & - & - & .14 & .05 & 2.87 & .002 \\
\hline Communication & - & - & - & -.08 & .05 & 1.49 & .07 \\
\hline Stage two & 194.84 & 8.52 & .004 & - & - & - & - \\
\hline Attention & - & - & - & .05 & .05 & .91 & .18 \\
\hline Communication & - & - & - & -.02 & .05 & .34 & .37 \\
\hline Culture & - & - & - & .08 & .03 & 3.08 & .001 \\
\hline
\end{tabular}

D refers to the deviance as an indication of fit by each model

Meanwhile, both the direct (i.e. culture with teacher gaze), $\mathrm{b}=.08$, s.e. $=.03$, $p=.01$, and total (i.e., culture without teacher gaze), $\mathrm{b}=.09$, s.e. $=.02, p<.001$, effects of culture were significant in circular mediation analysis.

\section{Discussion}

The present study was the first to explore the interpersonal meaning behind teachers' attentional and communicative gaze behaviour in class using the objective measure of eye-tracking glasses. The association between teacher' direct gaze towards students and students' perceptions of their interpersonal behaviour was investigated. Cultural comparisons of teacher interpersonal behaviour were made between East Asia (Hong Kong) and Western Europe (UK). Mediation by teacher gaze in culture's effect on student perceptions of teacher interpersonal behaviour was also examined. Furthermore, in accordance with the circular structure of the Interpersonal Circle for the Teacher (IPC-T), the present report presented appropriate statistical-circularanalyses. As a result, the expected interpersonal roles of teacher attentional gaze and communicative gaze (Hypothesis 1) were confirmed. Although culture distinguished teacher interpersonal behaviour as predicted, UK teachers were rated as more agentic (rather than more communing, as hypothesised) than Hong Kong teachers (Hypothesis 2). Culture was found to be a confound in the gaze-IPC-T relationship, predicting IPC-T alongside - rather than through - teacher gaze (Hypothesis 3).

As predicted in our first hypotheses, both attentional and communicative gaze predicted student perceptions of teacher interpersonal behaviour (Hypothesis 1). The more teachers directed attentional gaze towards students, the more agency students perceived in their teachers' interpersonal behaviour (i.e., anticlockwise-leaning, Fig. 1). Attentional gaze (i.e., teachers' information-seeking eye contact with students) thus increased with teachers' signals of classroom control and dominance, which echoed preceding literature (Cortina et al. 2015).

In contrast to attentional gaze, teacher interpersonal behaviour was rated as more communing with increasing communicative gaze directed at students. It seems that teachers' gaze towards students during information-giving (i.e., communicative) 
episodes is contextualised in cooperation with students rather than in confrontation (Argyle and Cook 1976; Jarick and Kingstone 2015; Terburg et al. 2011). In other words, teachers' gaze towards students in the classroom is likely to send communing signals to students and teachers' communicative gaze towards their students functions more in terms of social affiliation, more associated with friendliness, rather than messages of threat and dominance. Suggestions that teacher gaze towards students is linked with dominance, threat and aggression (e.g., Ellsworth 1975; Giacomantonio et al. 2018; Kleinke 1986) should therefore be tempered with considerations of the context in which eye contact occurs (Wu et al. 2014). Moreover, it appears that teachers capitalise on the natural pedagogy (Csibra and Gergely 2009) and the universal impact of direct gaze (Akechi et al. 2013), as they invite and encourage students to receive information by signalling communicative intent (Csibra 2010) via their communicative gaze.

Contrary to expectations in Hypothesis 2, UK (Western European) teachers received anticlockwise-leaning interpersonal behaviour ratings, suggesting greater agency than communion, whereas Hong Kong (East Asian) counterparts received clockwise-leaning ratings, suggesting greater communion than agency. Although past research has found East Asian teachers to be more agentic than Western teachers (e.g., Wei et al. 2015), with value placed on maintaining the power distance in accordance with the Confucian heritage of such settings (e.g., Leung 2014), results in the present study might be explained by East Asian students' heightened sensitivity to agentic behaviour (cf. cultural differences in classroom apprehension: Morishima 1981; Zhang et al. 1996). East Asian teachers might be aware of this apprehension around agentic teacher interpersonal behaviour and limit dominant signals-employing a restrained upper threshold of dominance-more than Western European teachers need to. It is also possible that Western students have greater resilience to controlling teacher behaviour, since the teacher-student power distance is less relevant in such cultural settings (Hofstede 1986). Alternatively, East Asian students may be more climatised to agentic teacher interpersonal behaviour, due to the norm of power distance in their settings and teachers' authoritative position. East Asian students may, in turn, be more likely to detect-and report-communing behaviour in their teachers than their UK counterparts would.

Hypothesis 3 anticipated that teacher gaze would mediate the link between culture and teacher interpersonal behaviour. Extant literature had widely documented that culture predicts differences in both teacher interpersonal behaviour (e.g., den Brok et al. 2006) and the use of direct gaze (Akechi et al. 2013; Jack et al. 2012; Senju et al. 2013). We therefore suspect that students' perceptions of teacher interpersonal behaviour might depend on the meanings that their cultural background imposes on teacher-student eye contact. We found an indirect effect of culture on student ratings of teacher interpersonal behaviour-but it was small and non-significant. Although bootstrapping meant that even small effect sizes from our mediation analyses could be used for meaningful conclusions (providing the small sample size and limited statistical power are born in mind), there may be no mediation pathway at all between culture and teacher interpersonal behaviour. It seems most likely that culture is a common cause for teacher gaze and their interpersonal behaviour as perceived by students. Rather than gaze being a separate entity to interpersonal 
behaviour, perhaps teacher gaze can, in future, be treated as a form of interpersonal behaviour. Research has already drawn many links between gaze and other interpersonal signals (e.g., Akechi et al. 2013; Einav and Hood 2008; Ohlsen et al. 2013). Subsequent research should focus on how 'interpersonal gaze' sits with other levels of teachers' interpersonal behaviour such as gesture and tone of voice.

\subsection{Limitations}

There was the danger of the eye-tracking glasses distracting participating teachers in this study. However, it has been argued that eye-tracking places only a minimal demand on participants (Glaholt and Reingold 2011). Moreover, teaching is such a demanding job in itself (Boshuizen 2016) that the eye-tracking glasses were unlikely to distract participants much, or for very long. A related study has been conducted regarding observational research, including the implications of researcher and research equipment presence on teachers' experience. Although teachers felt more nervous, their actual attention towards research-related aspects of the classroom was incredibly brief: after $1 \mathrm{~min}$ and $20 \mathrm{~s}$, teachers focused solely on instruction-related tasks and items. Students were also minimally affected (Praetorius et al. 2017), which addresses the additional possibility of a halo effect on students' views of teachers via their wearing of eye-tracking glasses. Informal conversations both with participating students and teachers support the likelihood that the distraction from the eye-tracker was similarly minimal. Furthermore, it should be noted that it is not conceivably possible for a less invasive set-up to be used than our presently reported design: most other observational studies would involve at least two video cameras in prominent positions and multiple researchers present in the classroom (Seidel et al. 2005). By bringing such minimally distracting technology into a naturally occurring scenario, we have conducted the most ecologically valid and least intrusive study possible.

This article presents circular analysis of teacher interpersonal behaviour as predicted by teacher gaze, expertise and culture. The use of circular analysis is more appropriate for the interpersonal circumplex compared with linear analysis as it allows for direct interpretation of the interpersonal circumplex. A downside, however, is that the standard errors computed for circular regression models are only approximate, as is common in many statistical models. This imprecision could be alleviated by moving to a Bayesian version of this model which uses MCMC for estimation (Mulder and Klugkist 2017). Another potential issue also to our circular analyses which used the angular position along the circumference of the IPC-T as the measure of general teacher interpersonal behaviour. An alternative approach to circular analysis is to go beyond the circumference and take into account the interpersonal 'intensity' of teacher behaviour, such that the position on the plane of the circle is also incorporated: that is, the distance between the centre and the edge of the interpersonal circle. Including the intensity of each teacher's IPC-T score would represent their interpersonal behaviour more comprehensively (Pennings et al. 2017). However, the angle on the circumference holds the most theoretical 
interest for inferring interpersonal behaviour, such that intensity adds little meaningful contribution.

\subsection{Implications and conclusion}

We propose a methodological implication for extension of the present research. The present research began investigating the relationship between teacher gaze and teacher interpersonal behaviour. We found summary values of teacher gaze to predict summary values of student rated teacher interpersonal behaviour. A logical next step will be for analytic techniques to be used to enable the changes in teacher gaze to be investigated for its impact on changing teacher interpersonal behaviour. One way to do this is to obtain summary metrics on, each, changes in teacher gaze and changes in teacher interpersonal behaviour. Another way to do this is to carry out dynamic analyses that resemble time series or cross-recurrence analysis that report how the two behavioural streams change alongside each other from moment to moment. Unfortunately, it is not possible to take these next steps in the present study since the only teacher interpersonal behaviour measure we have is aggregated by teacher through one-off student reports. As such, no changes in teacher interpersonal behaviour can be analysed using our data.

We additionally propose a theoretical implication from the present research. Although we anticipated teacher gaze to mediate culture's effect on teacher interpersonal behaviour, our results suggested that teacher gaze to be an outcome of culture alongside teacher interpersonal behaviour. Indeed, there is a notable quantity of literature that have already made the link between teachers' gaze (and other nonverbal behaviours) and students' experiences or perceptions of their interpersonal behaviour (e.g., Mazer et al. 2014; Titsworth et al. 2013), but not much on the notion that teachers' gaze might be one part of their interpersonal behaviour. We therefore recommend that future research takes teachers' gaze behaviour into consideration as one dimension of teacher interpersonal behaviour.

In conclusion, the present paper pioneers by taking the circular approach to both the validation and the statistical analysis of student-rated teacher interpersonal behaviour. In particular, circular statistical analysis revealed that teachers' attentional gaze towards students to predict increases in anti-clockwise leaning (i.e., more agentic) teacher interpersonal behaviour, whereas teachers' communicative gaze towards students predicted increases in clockwise-leaning (i.e., more communing) teacher interpersonal behaviour. Circular statistical analyses also revealed cultural differences in teacher interpersonal behaviour, namely that Hong Kong teachers were rated as more communing than UK teachers. Circular mediation analyses found teacher gaze not to mediate the link between culture and student-rated teacher interpersonal behaviour. Instead, culture emerged as a common cause confound in the path from teacher gaze to teacher interpersonal behaviour.

Funding The present research was funded by the Economic and Social Research Council, UK, Award Number 1367999. 


\section{Compliance with ethical standards}

Conflict of interest The authors declare that they is no conflict of interest.

Ethical approval Ethical approval was granted by the ethics committee at the Department of Education, University of York UK. All ethical requirements were fulfilled.

Informed consent Informed consent from all participants was obtained for this study. Informed consent obtained from all parents or Legally Authorised Representatives of student participants for the student data (self-reports of teachers' interpersonal behaviour).

Open Access This article is licensed under a Creative Commons Attribution 4.0 International License, which permits use, sharing, adaptation, distribution and reproduction in any medium or format, as long as you give appropriate credit to the original author(s) and the source, provide a link to the Creative Commons licence, and indicate if changes were made. The images or other third party material in this article are included in the article's Creative Commons licence, unless indicated otherwise in a credit line to the material. If material is not included in the article's Creative Commons licence and your intended use is not permitted by statutory regulation or exceeds the permitted use, you will need to obtain permission directly from the copyright holder. To view a copy of this licence, visit http://creativecommons.org/licen ses/by/4.0/.

\section{References}

Agostinelli, C., \& Lund, U. (2017). 'circular': Circular Statistics (version 0.4-93). Retrieved from https ://r-forge.r-project.org/projects/circular/. Accessed 1 March 2017.

Akechi, H., Senju, A., Uibo, H., Kikuchi, Y., Hasegawa, T., \& Hietanen, J. K. (2013). Attention to eye contact in the West and East: Autonomic responses and evaluative ratings. PLoS ONE, 8(3), e59312. https://doi.org/10.1371/journal.pone.0059312.

Alden, L. E., Wiggins, J. S., \& Pincus, A. L. (1990). Construction of circumplex scales for the inventory of interpersonal problems. Journal of Personality Assessment, 55(3-4), 521-536. https://doi. org/10.1080/00223891.1990.9674088.

Argyle, M., \& Cook, M. (1976). Gaze and mutual gaze. Oxford: Cambridge University Press.

Bentler, P. M. (1990). Comparative fit indexes in structural models. Psychological Bulletin, 107(2), 238-246.

Bentler, P. M. (1995). EQS structural equations program manual. Encino, CA: Multivariate Software.

Bentler, P. M., \& Bonett, D. G. (1980). Significance tests and goodness of fit in the analysis of covariance structures. Psychological Bulletin, 88(3), 588-606.

Blais, C., Jack, R. E., Scheepers, C., Fiset, D., \& Caldara, R. (2008). Culture shapes how we look at faces. PLoS ONE, 3(8), e3022. https://doi.org/10.1371/journal.pone.0003022.

Boshuizen, H. P. A. (2016). Teaching as regulation and dealing with complexity. Instructional Science, 44(3), 311-314. https://doi.org/10.1007/s11251-016-9377-x.

Brown, M., \& Cudeck, R. (1993). Alternative ways of assessing model fit. In D. M. Hawkins \& J. S. Long (Eds.), Testing structural equation models (pp. 136-162). Newbury Park, CA: Sage.

Browne, M. W. (1992). Circumplex models for correlation matrices. Psychometrika, 57(4), 469-497.

Chesebro, J. L. (2003). Effects of teacher clarity and nonverbal immediacy on student learning, receiver apprehension, and affect. Communication Education, 52(2), 135-147. https://doi.org/10.1080/03634 520302471 .

Cortina, K. S., Miller, K. F., McKenzie, R., \& Epstein, A. (2015). Where low and high inference data converge: Validation of CLASS assessment of mathematics instruction using mobile eye tracking with expert and novice teachers. International Journal of Science and Mathematics Education, 13(2), 389-403. https://doi.org/10.1007/s10763-014-9610-5.

Csibra, G. (2010). Recognizing communicative intentions in infancy. Mind \& Language, 25(2), 141-168. 
Csibra, G., \& Gergely, G. (2009). Natural pedagogy. Trends in Cognitive Sciences, 13(4), 148-153. https ://doi.org/10.1016/j.tics.2009.01.005.

Deci, E. L., Vallerand, R. J., Pelletier, L. G., \& Ryan, R. M. (1991). Motivation and education: The selfdetermination perspective. Educational Psychologist, 26(3-4), 325-346.

den Brok, P., Brekelmans, M., \& Wubbels, T. (2006). Multilevel issues in research using students' perceptions of learning environments: The case of the Questionnaire on Teacher Interaction. Learning Environments Research, 9(3), 199-213.

den Brok, P., van Tartwijk, J., Wubbels, T., \& Veldman, I. (2010). The differential effect of the teacherstudent interpersonal relationship on student outcomes for students with different ethnic backgrounds. British Journal of Educational Psychology, 80(2), 199-221. https://doi.org/10.1348/00070 9909X465632.

DePaulo, B. M., \& Friedman, H. S. (1998). Nonverbal communication. In D. T. Gilbert, S. T. Fiske, \& G. Lindzey (Eds.), The handbook of social psychology (pp. 3-40). New York: McGraw-Hill.

Eccles, J. S., Midgley, C., Wigfield, A., Buchanan, C. M., Reuman, D., Flanagan, C., et al. (1993). Development during adolescence: The impact of stage-environment fit on young adolescents' experiences in schools and in families. American Psychologist, 48(2), 90-101.

Efron, B., \& Tibshirani, R. J. (1994). An introduction to the bootstrap. Boca Raton: CRC Press.

Einav, S., \& Hood, B. M. (2008). Tell-tale eyes: Children's attribution of gaze aversion as a lying cue. Developmental Psychology, 44(6), 1655-1667. https://doi.org/10.1037/a0013299.

Ellsworth, P. C. (1975). Direct gaze as a social stimulus: The example of aggression. In P. Pliner, L. Krames, \& T. Alloway (Eds.), Nonverbal communication of aggression (pp. 53-75). Berlin: Springer.

Fabrigar, L. R., Visser, P. S., \& Browne, M. W. (1997). Conceptual and methodological issues in testing the circumplex structure of data in personality and social psychology. Personality and Social Psychology Review, 1(3), 184-203.

Franchak, J. M., Kretch, K. S., Soska, K. C., \& Adolph, K. E. (2011). Head-mounted eye tracking: A new method to describe infant looking. Child Development, 82(6), 1738-1750.

Giacomantonio, M., Jordan, J., Federico, F., van den Assem, M. J., \& van Dolder, D. (2018). The evil eye: Eye gaze and competitiveness in social decision making. European Journal of Social Psychology, 48(3), 388-396.

Glaholt, M. G., \& Reingold, E. M. (2011). Eye movement monitoring as a process tracing methodology in decision making research. Journal of Neuroscience, Psychology, and Economics, 4(2), 125.

Grassi, M., Luccio, R., \& Di Blas, L. (2010). CircE: An R implementation of Browne's circular stochastic process model. Behavior Research Methods, 42(1), 55-73.

Gurtman, M. B. (2009). Exploring personality with the interpersonal circumplex. Social and Personality Psychology Compass, 3(4), 601-619. https://doi.org/10.1111/j.1751-9004.2009.00172.x.

Hanley, M., Riby, D. M., Carty, C., Melaugh McAteer, A., Kennedy, A., \& McPhillips, M. (2015). The use of eye-tracking to explore social difficulties in cognitively able students with autism spectrum disorder: A pilot investigation. Autism, 19(7), 868-873. https://doi.org/10.1177/1362361315580767.

Hofstede, G. (1986). Cultural differences in teaching and learning. International Journal of Intercultural Relations, 10(3), 301-320. https://doi.org/10.1016/0147-1767(86)90015-5.

Horowitz, L. M., \& Strack, S. (2010). Handbook of interpersonal psychology: Theory, research, assessment, and therapeutic interventions. Hoboken, NJ: Wiley.

Hu, L.-T., \& Bentler, P. M. (1998). Fit indices in covariance structure modeling: Sensitivity to underparameterized model misspecification. Psychological Methods, 3(4), 424-453.

Hu, L. T., \& Bentler, P. M. (1999). Cutoff criteria for fit indexes in covariance structure analysis: Conventional criteria versus new alternatives. Structural Equation Modeling: A Multidisciplinary Journal, $6(1), 1-55$.

Jack, R. E., Garrod, O. G., Yu, H., Caldara, R., \& Schyns, P. G. (2012). Facial expressions of emotion are not culturally universal. Proceedings of the National Academy of Sciences, 109(19), 7241-7244.

Jarick, M., \& Kingstone, A. (2015). The duality of gaze: Eyes extract and signal social information during sustained cooperative and competitive dyadic gaze. Frontiers in Psychology, 6, 1423.

Johnson, S., \& Miller, A. (2002). A cross-cultural study of immediacy, credibility, and learning in the US and Kenya. Communication Education, 51(3), 280-292.

Jöreskog, K. G., \& Sörbom, D. (1981). LISREL V: Analysis of linear structural relations by the method of maximum likelihood. Chicago: International Educational Services.

Kelly, D., Jack, R., Blais, C., Caldara, A.-S., Rossion, B., Scheepers, C., et al. (2008). Inverting faces does not abolish cultural diversity in eye movements. Journal of Vision, 8(6), 643-643. 
Kerssen-Griep, J., \& Witt, P. L. (2012). Instructional feedback II: How do instructor immediacy cues and facework tactics interact to predict student motivation and fairness perceptions? Communication Studies, 63(4), 498-517. https://doi.org/10.1080/10510974.2011.632660.

Kleinke, C. L. (1986). Gaze and eye contact: A research review. Psychological Bulletin, 100(1), 78.

Larsen, R. J., \& Diener, E. (1992). Promises and problems with the circumplex model of emotion. In M. S. Clark (Ed.), Review of personality and social psychology: Emotion (Vol. 13, pp. 25-59). Newbury Park: Sage.

Lawson, M. A., \& Lawson, H. A. (2013). New Conceptual frameworks for student engagement research, policy, and practice. Review of Educational Research, 83(3), 432-479. https://doi. org/10.3102/0034654313480891.

Leung, F. K. (2014). What can and should we learn from international studies of mathematics achievement? Mathematics Education Research Journal, 26(3), 579-605.

Lüdtke, O., Robitzsch, A., Trautwein, U., \& Kunter, M. (2009). Assessing the impact of learning environments: How to use student ratings of classroom or school characteristics in multilevel modeling. Contemporary Educational Psychology, 34(2), 120-131. https://doi.org/10.1016/j.cedps ych.2008.12.001.

MacKinnon, D. P., Lockwood, C. M., Hoffman, J. M., West, S. G., \& Sheets, V. (2002). A comparison of methods to test mediation and other intervening variable effects. Psychological Methods, 7(1), 83.

Mainhard, M. T., Brekelmans, M., \& Wubbels, T. (2011). Coercive and supportive teacher behaviour: Within- and across-lesson associations with the classroom social climate. Learning and Instruction, 21(3), 345-354. https://doi.org/10.1016/j.learninstruc.2010.03.003.

Mallinckrodt, B., Abraham, W. T., Wei, M., \& Russell, D. W. (2006). Advances in testing the statistical significance of mediation effects. Journal of Counseling Psychology, 53(3), 372.

Mardia, K. V., \& Jupp, P. E. (2009). Directional statistics (Vol. 494). Hoboken: Wiley.

Markus, H. R., \& Kitayama, S. (1991). Culture and the self: Implications for cognition, emotion, and motivation. Psychological Review, 98(2), 224-253.

Mason, M. F., Tatkow, E. P., \& Macrae, C. N. (2005). The look of love: Gaze shifts and person perception. Psychological Science, 16(3), 236-239.

Matsumoto, D., Kudoh, T., Scherer, K., \& Wallbott, H. (1988). Antecedents of and reactions to emotions in the United States and Japan. Journal of Cross-Cultural Psychology, 19(3), 267-286.

Maulana, R., Opdenakker, M. C., \& Bosker, R. (2014). Teacher-student interpersonal relationships do change and affect academic motivation: A multilevel growth curve modelling. British Journal of Educational Psychology, 84(3), 459-482. https://doi.org/10.1111/bjep.12031.

Mazer, J. P., McKenna-Buchanan, T. P., Quinlan, M. M., \& Titsworth, S. (2014). The dark side of emotion in the classroom: Emotional processes as mediators of teacher communication behaviors and student negative emotions. Communication Education, 63(3), 149-168. https://doi.org/10.1080/03634 523.2014.904047.

McCarthy, A., Lee, K., Itakura, S., \& Muir, D. W. (2006). Cultural display rules drive eye gaze during thinking. Journal of Cross-Cultural Psychology, 37(6), 717-722.

McCarthy, A., Lee, K., Itakura, S., \& Muir, D. W. (2008). Gaze display when thinking depends on culture and context. Journal of Cross-Cultural Psychology, 39(6), 716-729.

McDonald, R. P., \& Marsh, H. W. (1990). Choosing a multivariate model: Noncentrality and goodness of fit. Psychological Bulletin, 107(2), 247-255. https://doi.org/10.1037/0033-2909.107.2.247.

Miellet, S., Vizioli, L., He, L., Zhou, X., \& Caldara, R. (2013). Mapping face recognition information use across cultures. Frontiers in Psychology, 4, 34.

Miller, A. D., \& Murdock, T. B. (2007). Modeling latent true scores to determine the utility of aggregate student perceptions as classroom indicators in HLM: The case of classroom goal structures. Contemporary Educational Psychology, 32(1), 83-104. https://doi.org/10.1016/j.cedpsych.2006.10.006.

Morishima, J. (1981). Special employment issues for Asian Americans. Public Personnel Management, 10(4), 384-392. https://doi.org/10.1177/009102608101000406.

Mulder, K., \& Klugkist, I. (2017). Bayesian estimation and hypothesis tests for a circular generalized linear model. Journal of Mathematical Psychology, 80, 4-14.

Ohlsen, G., van Zoest, W., \& van Vugt, M. (2013). Gender and facial dominance in gaze cuing: Emotional context matters in the eyes that we follow. PLOS ONE, 8(4), e59471.

Palmer, D. J., Stough, L. M., Burdenski, J. T. K., \& Gonzales, M. (2005). Identifying teacher expertise: An examination of researchers' decision making. Educational Psychologist, 40(1), 13-25. https:// doi.org/10.1207/s15326985ep4001_2. 
Pennings, H. J. M., Brekelmans, M., Sadler, P., Claessens, L. C. A., van der Want, A. C., \& van Tartwijk, J. (2017). Interpersonal adaptation in teacher-student interaction. Learning and Instruction. https:// doi.org/10.1016/j.learninstruc.2017.09.005.

Pennings, H. J. M., \& Mainhard, T. (2016). analyzing teacher-student interactions with state space grids. In M. Koopmans \& D. Stamovlasis (Eds.), Complex dynamical systems in education: Concepts, methods and applications (pp. 233-271). Cham: Springer International Publishing.

Pewsey, A., Neuhäuser, M., \& Ruxton, G. D. (2013). Circular statistics in R. Oxford: Oxford University Press.

Pianta, R. C., Hamre, B. K., \& Allen, J. P. (2012). Teacher-student relationships and engagement: Conceptualizing, measuring, and improving the capacity of classroom interactions. In S. L. Christenson, A. L. Reschly, \& C. Wylie (Eds.), Handbook of research on student engagement (pp. 365-386). London: Springer.

Pintrich, P. R., Roeser, R. W., \& De Groot, E. A. (1994). Classroom and individual differences in early adolescents' motivation and self-regulated learning. The Journal of Early Adolescence, 14(2), 139-161.

Praetorius, A.-K., McIntyre, N. A., \& Klassen, R. M. (2017). Reactivity effects in video-based classroom research: An investigation using teacher and student questionnaires as well as teacher eye-tracking. Zeitschrift für Erziehungswissenschaft, 20(1), 49-74. https://doi.org/10.1007/s11618-017-0729-3.

R Core Team. (2017). R: A language and environment for statistical computing. Vienna: R Foundation for Statistical Computing. Retrieved from https://www.R-project.org/. Accessed 1 March 2017.

Richmond, V., Gorham, J., \& McCroskey, J. (1987). The relationship between selected immediacy behaviors and cognitive learning. In M. McLaughlin (Ed.), Communication yearbook (Vol. 10, pp. 547590). Beverly Hills, CA: Sage.

Seidel, T., Prenzel, M., \& Kobarg, M. (2005). How to run a video study. Münster: Waxmann Verlag.

Senju, A., Vernetti, A., Kikuchi, Y., Akechi, H., \& Hasegawa, T. (2013). Cultural modulation of face and gaze scanning in young children. PLoS ONE, 8(8), e74017.

Shrout, P. E., \& Bolger, N. (2002). Mediation in experimental and nonexperimental studies: New procedures and recommendations. Psychological Methods, 7(4), 422.

Slof, B., Nijdam, D., \& Janssen, J. (2016). Do interpersonal skills and interpersonal perceptions predict student learning in CSCL-environments? Computers \& Education, 97, 49-60.

Sun, X., Mainhard, T., \& Wubbels, T. (2018). Development and evaluation of a Chinese version of the Questionnaire on Teacher Interaction (QTI). Learning Environments Research, 21(1), 1-17.

Terburg, D., Hooiveld, N., Aarts, H., Kenemans, J. L., \& van Honk, J. (2011). Eye tracking unconscious face-to-face confrontations: Dominance motives prolong gaze to masked angry faces. Psychological Science, 22(3), 314-319.

Titsworth, S., McKenna, T. P., Mazer, J. P., \& Quinlan, M. M. (2013). The bright side of emotion in the classroom: Do teachers' behaviors predict students' enjoyment, hope, and pride? Communication Education, 62(2), 191-209.

Turman, P. D., \& Schrodt, P. (2006). Student perceptions of teacher power as a function of perceived teacher confirmation. Communication Education, 55(3), 265-279.

Uchida, Y., \& Kitayama, S. (2009). Happiness and unhappiness in east and west: Themes and variations. Emotion, 9(4), 441-456.

Van Tartwijk, J., Brekelmans, M., \& Wubbels, T. (1998). Student' perceptions of teacher interpersonal style: The front of the classroom as the teacher's stage. Teaching and Teacher Education, 14(6), 607-617.

Vansteenkiste, M., Simons, J., Lens, W., Sheldon, K. M., \& Deci, E. L. (2004). Motivating learning, performance, and persistence: the synergistic effects of intrinsic goal contents and autonomysupportive contexts. Journal of Personality and Social Psychology, 87(2), 246-260. https://doi. org/10.1037/0022-3514.87.2.246.

Wei, M., Brok, P., \& Zhou, Y. (2009). Teacher interpersonal behaviour and student achievement in English as a Foreign Language classrooms in China. Learning Environments Research, 12(3), 157-174. https://doi.org/10.1007/s10984-009-9059-6.

Wei, M., Zhou, Y., Barber, C., \& den Brok, P. (2015). Chinese students' perceptions of teacher-student interpersonal behavior and implications. System, 55, 134-144.

Wirth, J. H., Sacco, D. F., Hugenberg, K., \& Williams, K. D. (2010). Eye gaze as relational evaluation: Averted eye gaze leads to feelings of ostracism and relational devaluation. Personality and Social Psychology Bulletin, 36(7), 869-882. https://doi.org/10.1177/0146167210370032. 
Wu, D. W.-L., Bischof, W. F., \& Kingstone, A. (2014). Natural gaze signalling in a social context. Evolution and Human Behavior, 35, 211-218.

Wubbels, T. (1993). Teacher-student relationships in science and mathematics classes. What Research Says to the Science and Mathematics Teacher, 11, 1-8.

Wubbels, T., Brekelmans, M., den Brok, P., Wijsman, L., Mainhard, T., \& van Tartwijk, J. (2014). Teacher-student relationships and classroom management. In E. J. Sabornie (Ed.), Handbook of classroom management (pp. 363-386). Oxon: Routledge.

Wubbels, T., Brekelmans, M., Mainhard, T., den Brok, P., \& van Tartwijk, J. (2016). Teacher-student relationships and student achievement. In K. R. Wentzel \& G. B. Ramani (Eds.), Handbook of social influences in school contexts: Social-emotional, motivation, and cognitive outcomes (pp. 127-145). New York: Routledge.

Zhang, Y., Butler, J., \& Pryor, B. (1996). Comparison of apprehension about communication in China and the United States. Perceptual and Motor Skills, 82(3C), 1168-1170.

Publisher's Note Springer Nature remains neutral with regard to jurisdictional claims in published maps and institutional affiliations.

Nora A. McIntyre is currently a Senior Research Associate in the Faculty of Education, University of Cambridge, UK. Her research interests are in the quantitative analysis of intensive data for real-world, contextualised investigations of classroom learning in relation to culture and income inequalities.

Kees Tim Mulder is a statistician who is affiliated with the Social and Behavioural Sciences in Utrecht University, The Netherlands. He specialises in circular statistics and mediation analyses.

M. Tim Mainhard is an Associate Professor with the Department of Education and Pedagogy in the School of Social and Behavioural Sciences at Utrecht University, The Netherlands. His interests are in intensive data analysis for investigations of classroom affect and Interpersonal Theory. 